\title{
Degrees or Diplomas? Two Scenarios in an Environmental Management Programme in a Faculty of Applied Sciences
}

\author{
Tholang Maqutu \\ Cape Peninsula University of Technology \\ maqutu@@put.ac.za \\ Bonita Kleyn-Magolie \\ Cape Peninsula University of Technology \\ kleynmagolieb@cput.ac.za \\ De Wet Schutte \\ Cape Peninsula University of Technology \\ schutted@cput.ac.za
}

Doi:10.5901/mjss.2014.v5n23p1419

\begin{abstract}
The Management of a Faculty of Applied Sciences in a South African university of technology is keen on the Faculty offering degrees rather than the current system of diploma qualifications. But different programmes have different structures and purposes which may make them more or less suitable as degree qualifications. All the current programmes are in Muller's (2009) terms 'outward-looking' and involve applied theory as they are aimed at developing students directly for careers. However, some careers involve high levels of scientific theory which would need to be taught in a vertical and cumulative fashion over a longer period. These sorts of diploma qualifications, for example, biotechnology, may be quite suited to be developed as degree qualifications. Even though other careers, such as environmental management, involve the natural sciences, they have a strong focus on the social sciences. Such diploma qualifications may be more difficult to convert to degree programmes as it involves two different, sometimes considered to be opposite sciences, namely the natural and human sciences. The article aims to examine the current drivers at play in the field of environmental management and what effects the introduction of degrees may have on these actors. It also examines possible changes and how these could impact on the introduction of degree holding workers and the degree programme itself in a university of technology using scenario methodology. These will include the professional environments and the nature of the knowledge taught in the fields.
\end{abstract}

Keywords: Degree, diploma, scenario methodology, university of technology, forms of knowledge, vocational curricula

\section{Introduction}

Prior to 2004, the tertiary education system in South Africa was offered by universities (higher education) and technikons (vocational education). The naming of tertiary education institutions changed in 2004, when all technikons were renamed universities of technology (UoT). This process of re-naming is not new, as calls for a common name, namely, 'universities' for all tertiary institutions were also made back in the 1970s in Australia (Young, 1975).

In 2007, the then South African Department of Education and Training introduced the Higher Education Qualifications Framework (HEQF). According to the HEQF all existing qualifications and programmes offered by higher education institutions had to be aligned with this framework by 2009. None of the current UoT- type qualifications such as the National Diploma and Bachelor of Technology featured on the HEQF. Therefore, a new suite of "HEQF - compliant" qualifications needed to be designed by the UoTS. As time went by, the UoTs could not comply by the required date and a transitional period was granted to ensure full compliance with the HEQF policy.

The primary purpose of tertiary education is to skill the workforce and citizens (Beddie, 2010) and the main aim of the Higher Education Qualification Council (HEQC) was to transform higher education in South Africa by creating a single qualifications framework for a single coordinated higher education sector (Republic of South Africa, 1997). The implementation of this policy provided UoTs with the opportunity to reflect on their current qualifications offerings and to allow them to engage in a major curriculum reconstruction exercise, referred to as recurriculation in a South African 
higher education context.

This article, firstly, examines what forces are at play in pushing for and against a degree or diploma programmes in a Faculty of Science or Applied Sciences programme at a university of technology. This should include the professional environments and the nature of the knowledge taught in the fields. Secondly, findings made from an analysis of data solicited from the environmental management programme's situation/needs to generated two contrasting scenarios will be presented. In this article the scenario method will be used to reflect on the possible impact of UoTs abandoning the diploma qualification option in favour of a degree qualification in the case of environmental management.

\section{Theoretical Framework: Diplomas or Degrees in Universities of Technology}

In the University of Technology the Management of the Faculty of Applied Sciences is keen on the Faculty offering degrees rather than the current system of diploma qualifications. However, different programmes have different structures and purposes which may make them more suitable as degree programmes. All the current programmes in the faculty, for example, agriculture, chemistry, environmental management and food technology are, in Muller's (2009) terms, 'outwardlooking' and involve applied theory and practice-based knowledge as they are aimed at developing students directly for careers. However, some careers involve high levels of academic scientific theory which would need to be taught in a hierarchical cumulative fashion over a longer period (Shay \& Steyn, 2013; Muller, 2013; 2009).

The Department of Higher Education and Training's Higher Education Qualification Sub-framework (HEQSF) (Republic of South Africa, 2013) differentiates between degree and diploma qualifications. A diploma is a 2 or 3 years programme carrying 240 and 360 credits respectively. The exit level for the two diploma qualifications is Level 6 on the South African National Qualification Framework (NQF). Currently environmental management, which is the focus of this study, is a 3-year diploma qualification which amounts to 360 credits.

Diplomas prepare graduates with field specific skills and knowledge. They are aligned towards vocational training leading directly to the job market (Beddie, 2010; Kloppenborg, 2010). The distinguishing features of the diploma qualifications include their being heavily teacher directed, didactically delivered with minimum encouragement to critical thinking and reflective practice (Kell, 2006). Diploma qualifications prepare graduates for more practice-based knowledge derived from the field of practice without rich discipline background knowledge. The application of knowledge and skills experiences is in the workplace context for diploma graduates (Winberg, 2012; Muller, 2009). Knowledge in these qualifications must be directly linked to work experiences in order for the diploma graduates to be described as readily employable (Gamble, 2006; Young, 1975). Research is not part of this qualification (Winberg, 2012; Warring, 2011; Kloppenborg, 2010; Kell, 2006). In short, a diploma prepares graduates for what some scholars describe as "more specialised practice" (Muller, 2009; Winberg, 2012).

On the other hand, degrees at traditional universities are typically 3 or 4 year qualifications with 360 and 480 credits at NQF exit Levels 7 and 8, respectively. Degrees often include appropriate research in the field of study for degree graduates (Warring, 2011; Government of South Africa, 2012). Degree holders often display critical thinking and reflective practice skills and engage effectively in lifelong learning and professional activities such as continuous professional development (CPD) (Kell, 2006). The purpose of degree qualification is to provide a well grounded, broad education that equips graduates with the knowledge base, theory and methodology in the discipline of study (Republic of South Africa, 2013). Loyalty degree programmes are aimed towards building disciplinary knowledge (Shay, 2012). Consequently, degrees contain more pure and applied disciplinary knowledge. They, therefore prepare students for a broader field of practice while diplomas prepare graduates for more specific field of applied practice (Muller, 2009; Winberg, 2012).

Warring (2011) highlights other distinguishing attributes between the two qualification types, namely, diploma and degree programmes, which include degrees of abstraction, levels of complexity and depth in the discipline knowledge and skills and learner autonomy. Degrees are taught at a higher cognitive level compared to diploma qualifications. However, although in some countries such as Australia, clear distinctions between the two qualification are distinguished, (Australian Qualification Framework, 2013), Warring (2011) failed to find any difference in learning levels in the specific qualifications in a New Zealand polytechnic. Similar findings were observed in the case of nursing's practices for degree and diploma qualifications in the United Kingdom (Ashworth, Gerrish, Hargreaves \& McManus, 1999). In South Africa the Department of Higher Education and Training distinguishes between diplomas and degrees in the characteristic of graduates and levels and types of competencies (Republic of South Africa, 2013). But, in the case of South Africa, the degree and diploma pathways are regarded as being on incompatible trajectories.

The question that this study seeks to answer is whether the Faculty should offer only degrees instead of diplomas, and put more effort in pursuing research, as UoTs may argue that they are no longer technikons, but are now universities. 
For example, curriculum designers may argue that a programme such as biotechnology is more suited to be offered as a degree compared to environmental management. Biotechnology, by nature, uses mathematics and the natural sciences as fundamentals resulting with it being highly structured and may be well suited to be developed as degree programmes. Modern biotechnology is a relatively new field of specialization and is a rapidly evolving discipline, and all its composite subjects build logically and incriminatory on one another in the form of prerequisites. The discipline requires knowledge and skills that are mainly theoretical as one progresses through the structure. However, it is also considered to impart higher levels of sophisticated skills that would normally be beyond the diploma requirements (Muller, 2013; Beddie, 2010). In addition, the degree will prepare students more adequately to keep up and contribute to the field than a diploma with its traditional focus on applied knowledge.

Moreover, the broad nature of the knowledge that is provided in degree prepares students for sophisticated, extensive broad knowledge before specializing in specific fields of study, and is supported by the learning outcomes given in the postgraduate research studies programmes (Warring, 2011; Kloppenborg, 2010; Kell, 2006). Alternatively, careers such as environmental management and consumer science involve science, but they do so in a relatively loose manner as they include a strong focus on the social sciences. Such diploma qualifications may be more difficult to convert to bachelor's degree qualifications.

\section{Data Collection and Analysis Procedures}

Given the purpose of the article and the general dynamic nature of educational systems curricula to adapt to the societal needs, (Snoek, 2003) this article employed the scenario methodology. Scenarios are future oriented and help educational systems not to provide solutions that lag behind the societal needs. Curriculum has to project into the future because education itself prepares for the future (Snoek, 2003). As scenarios are a by-product of learning, some theorists predict that in the future, scenario methodology will develop into a more evidenced-based future orientated research methodology (Wright, Cairns, and Bradfield, 2013; Snoek, 2003).

This article uses the findings by the environmental management programme needs analysis to generate and contrast two imaginary, but plausible scenarios (Önkal, et al, 2013). Data were solicited from a needs analysis that was undertaken for the environmental management programme for the purposes of curriculum reconstruction. The programme consulted with different relevant stakeholders, namely, students, alumni, industry, academics and environmental organisations to assess the quality of the current programme. The curriculum was adjusted according to the feedback of the stakeholders.

\section{Scenario Pointers from the Environmental Management Need Analysis}

The main findings of the analysis were the following pointers that were derived from the interaction with the above information sources:

- Graduates who have degrees are much more respected in the corporate environment than diploma graduates.

- Students studying for degrees are exposed to a higher level of learning that enables them to think globally and to implement environmental research at a high level. Traditionally, they also qualify for better positions within industry.

- An organisation hiring a diploma graduate, has expectations of someone with basic levels of knowledge in a subject, with little experience or expertise in being able to interpret facts or apply knowledge. Conversely, an organisation hiring a graduate with a degree expects a person with a knowledge base that can withstand robust enquiry and apply academic rigour when required. A degree graduate should be able to conduct research required, and demonstrate empirical knowledge of the subject/issue researched.

- In order for graduates to be effective at work, they are expected to have a complete qualification which can be recognised at a professional level. A degree also enhances the graduate's self confidence when competing with other practitioners in the corporate world.

It can be concluded from the findings of the environmental management programme needs analysis above that in general the stakeholders prefer degrees over diploma programmes. Should that preference be followed? Do the stakeholders understand the implications of all the UoTs only offering degrees? In particular, would there be enough practically skilled employees in environmental management within industry?

Historically, technikons were aimed at providing practical skills based or vocational higher education to students who did not meet the entry requirements for Bachelor degrees at universities but had results that were too good for 
admission into Further Education and Training Colleges (FET). In South Africa the majority of these students come from disadvantaged and poor backgrounds.

Traditionally, degrees are offered at traditional universities, whilst certificates and diplomas are offered at Technikons and higher certificates at FTE Colleges. From this premise the National Senior Certificate (NSC) indicates whether a student qualifies either for admission to a bachelor's degree, diploma or higher certificate. It is against this background that the following questions are asked. If UoTs only offered degrees, how will the students who qualify for a diploma, be accommodated in the South African Higher Education System? What will happen to these young adults who have completed their NSC, but do not qualify for university admission?

FET Colleges are an option for students who qualify for admission to a diploma. However, FET Colleges offer qualifications at a National Qualifications Framework (NQF) level four up to level five, which is equivalent to a first year level of a three year diploma. In addition, FET Colleges do not offer all the qualifications that are offered at UoTs, which may restrict students' career choice and upward mobility. The question that arises from the above situation is whether students who qualify for diplomas will be forced to go to FET Colleges, choose careers that they are not interested in or join the labour force without any qualifications or vocational skills? South Africa has one of the highest unemployment rates in the world. Statistics South Africa (2012) for 2011 census revealed that the country's overall unemployment rate was $29,8 \%$. The result of not accommodating these potential diploma students will aggravate the already high unemployment rate in South Africa and may even further enhance the current levels of poverty and crime in South Africa. Are we setting these young unqualified adults up for failure? These are the very problems that the South African government is trying to resolve.

South Africa could adapt a compromise solution as suggested by Young (2009) in the case of Australia where it was proposed that the less prepared students can significantly enhance completion of their studies at university education through a diploma pathway. In South Africa these would be the type of students who qualify for 'diploma' or 'higher certificate' at a NSC level. Thus, the diploma pathway will enhance the success rates of these students in a traditional university environment (Young, 2009). In addition, this pathway will enable these students to 'kill two birds with one stone'. Firstly it would provide students access into university degree programmes while at the same time skilling them for the world of work (Gamble, 2006; Young, 2009).

From this it can be concluded that there is a definite need for UoTs to continue to offer diploma qualifications to accommodate this cohort of NSC holders. Given that recurriculation appears to be inevitable as a mandate of HEQF, the next question is how the objectives and background goals of the diploma and certificate systems could still be met under a degree system. It is not clear how that should be done. Consequently, it would be useful to explore the possibilities using the scenario approach of the present development of a degree in environmental management.

\subsection{Scenario 1}

Biotechnology followed the degree pathway because of the nature of the discipline. The recurriculation for biotechnology to a degree was used as a model for the other departments in the faculty of Applied Sciences. This programme is by nature fundamentally "traditional sciences" orientated and therefore requires an exhaustive theoretical knowledge base. The degree programme is designed to provide students with sophisticated, extensive broad knowledge before specializing in specific fields with progression into postgraduate research studies (Kell, 2006). The vertical progression is supported by the learning outcomes are typically associated with traditional degree postgraduate study programmes.

From discussions with lecturers involved in the environmental management, consumer science and some of the other departments in the same faculty, it became clear that they feel that the nature of their programmes is more geared towards diploma qualifications. The proponents of the degree pathway argue that the university status would require that degrees grounded in the fundamental sciences should be offered. In response to this argument, the challenge for environmental management is that it is a multidisciplinary based programme which involves not only diverse natural sciences subjects, but also the human sciences, economic sciences and law. Though there had been wide consultation with various stakeholders, there were no general consensus of which segment and concurrent employment opportunities are to be focussed upon in the curriculum due to the multidisciplinary nature of the field. As the programme is presently largely segmented and includes a little of everything, the question remains whether UoTs should produce graduates that would occupy middle-level jobs in companies, consultancies or be more focussed on policy staff in government or public service?

Furthermore, the curriculum is devoted to projects with more problem- and practice- based-orientation and includes a project that should address the interdisciplinary challenge of environmental issues. The consequence of this is that students in environmental management do not follow a specific discipline, but are rather developed into environmental 
management generalists.

For environmental management degree holders that enter the job market, their qualifications seem to be more attractive for government agencies (Young, 1975). But, these applicants compete with graduates from a variety of disciplines such as geology, economics, chemistry and law. The UoT environmental management graduates reported that that although their degrees may appear to be more attractive, they are not specialists in any of the aforementioned disciplines, but are generalist. The result of this is that the UoT environmental management graduates feel at a disadvantage to graduates that have specialised in specific disciplines with a more in-depth knowledge of their particular fields. When the current environmental management students hear about the afore mentioned problems the graduates are facing, they raise the issue with the institution and insist on the curriculum being reviewed to make their qualification more suitable for the market.

After consultation with staff and other relevant stakeholders, it was decided to stream the programme, allowing students some level of specialisation. After many discussions it was decided to divide the programme into three streams namely, environmental resource management, water quality management and air quality management. In the first year all the environmental management students will enrol for all the subjects and from the second year the programme will be divided into the three streams. This would allow students to become specialists in any one of the three streams after successful completion of the first year of study.

\subsection{Scenario 2}

The management of the Faculty of Applied Sciences wants the environmental management programme to become more scientific (as it is hosted in the Faculty of Applied Sciences), but the department resists. Some lecturers argue that there is the challenge of interdisciplinarity, and others emphasizing that the responsibility of a UoT is to offer training for potential young people that do not meet the admission requirement into degree qualifications. This scenario also resonates with the higher echelon who wants to be serious about the contribution of Higher Education to transformation.

A compromise is made allowing environmental management to continue as a diploma qualification, provided that there is some improvement in the scientific quality of the diploma qualification. This would be achieved by developing relevant and responsive curricula which integrates the needs of various stakeholders and takes into consideration employment trends of the country, industry needs and also new developments in the field. The improved curricula will provide the environmental management graduates with a competitive edge as being moulded according to the stakeholders' needs and through this enhance the viability and long term sustainability of the programme. A further part of the compromise is to create an integrated degree in environmental management, which would be interfaculty, whilst led and administered by the programme of environmental management.

Naturally the combination of present and new tasks during this transformation phase will put an additional workload with more stress on the staff. However, some of the staff members did express their relieve when the vice-chancellor was able to obtain funding from the Department of Higher Education and Training (DHET) for the development of the interfaculty degree in environmental management which resulted in a project leader to be seconded to manage this recurriculation project. The University presented the project to the DHET, showcasing the innovativeness of this UoT. This presentation created high levels of expectations as a possible way forward in the recurriculation of a typical multidisciplinary subject such as environmental management.

As with other attempts at interfaculty teaching and training programmes worldwide, it turns out to be difficult to get everybody across faculties and departments working together on a project that will ultimately be hosted in a single specific department. Because of this anticipated situation, the project leader proposes to work in two steps. First, to use what has been achieved already to create a high-level post-graduate training programme for capacity building and staff development, which also builds on specificities of Southern-African countries. Second, if successful, an attempt will be made to have a degree curriculum as well. It could be expected that by that time the University and its faculties would have evolved further, and the reality of interdisciplinary approaches in teaching and research would have evolved into growing concerns, including a search of appropriate organisational and administrative forms.

Simultaneous, while appreciated, the diploma will come under criticism in that its contribution to the emancipation of the previously disadvantaged majority students and drive towards social transformation would require more varied learning methodologies, including issuing dedicated certificates to students. Such a development towards what others might regard as 'downward' was seriously considered. While a few experimental set-ups were agreed upon, it could also lead to a further discussion about the nature of a UoT in the South African HE system in search of an answer to the root question, namely: Would the purpose of the qualification be about technology, or about work-related learning for all levels of the knowledge society? 


\section{Discussion}

From this study it seems that the main finding for the needs analysis conducted by the programme of environmental management was that stakeholders would prefer graduates with degrees because of the status attached (Beddie, 2010; Edwards \& Miller, 2008; Young, 1975). The purposes of diploma qualifications are different from those of degree offerings as the demands and expectations of degrees differ from those for diploma qualifications. To overcome perceived stakeholder driven preference, there would be a need to replace the deliberate didactic teaching methodologies used in typical diploma qualifications, by interactive methodologies that would promote inquiry, critical and reflective thinking vital to degree qualifications.

Edwards and Miller found evidence suggesting that there was an increasing emphasis given to educational rather than occupational relevance in vocational curriculum (2008). This resulted in a phenomenon often referred to as 'academic drift' (Sá \& Litwin, 2011; Lepori, 2008; Jinabhai, 2003; Kyvik \& Skodvin, 2003; Pratt, 1997). Other serious impacts resulting from 'academic drift' have been suggested in the second scenario elsewhere. One consequences of 'academic drift' is the tendency by colleges (or UoTs) to move from solely providing teaching courses to increasing emphasis on research and research based degrees (Kyvik \& Skodvin, 2003). Alternatively it (academic drift) may be regarded as the valuing and uptake of academic practices at the expense of vocational qualifications and practices (Edwards \& Miller, 2008). According to Kloppenborg and Young, academic drift has direct implications on financial, human and physical resources (Kloppenborg, 2010; Young; 2009). In terms of human resources, this would include the need to re-train teaching staff members pedagogically bearing in mind they are adept to didactic teaching at a diploma level to enable them to facilitate learning to a new 'brand' of students at degree level and research and improve their academic qualification in their respective disciplines (Lepori, 2008; Kell, 2006; Kyvik \& Skodvin, 2003; Pratt, 1997).

The 'Academification' of diploma's vocational curricula may have as a result that these programmes become too scientific, and as a consequence lose touch with reality and societal needs (both students and industry). Shay (2012) proposes what she called future curricula, that is, curriculum that puts discipline to work, therefore equipping and enabling graduates to resolve most critical problems. She asserts that some diploma qualifications, for example, those that are in the 'soft applied sciences', are highly susceptible to phenomenon of being made 'too scientific'. However, the result of it all cannot escape the need that resources such as the library would need to be continuously upgraded in order to enable them to provide for the existing diploma and the new cohort of degree students and lecturers (Kloppenborg, 2010; Young; 2009).

Despite everything, our study explores two scenarios in an endeavour to identify the best option for the programme of environmental management in response to this demand.

In scenario 1: A degree is implemented and industry responds positively to the students multidisciplinary skills. The advantage to industry and the world of work is that the multidisciplinary nature of the environmental management programme enables graduates to work across different fields. These graduates would already have had exposure to integrated projects that relates directly to the workplace during their studies at university. This experience will make these graduates more employable as technicians or technologists. The benefit for industry would be a graduate that has a holistic view of the world of work.

However, these graduates themselves feel inadequate compared to graduates that have specialised in some related field. These graduates are at a disadvantage when competing for promotion into senior positions as they will have the technical knowledge, but not the strategic and vocational research skills. The qualification will not provide students with what Shay (2013) refers to as powerful knowledge that students need to gain epistemologically access into their fields of study.

In scenario 2: In this scenario the institution will produce graduates who will work at all levels within industry from occupying white collar jobs to technicians. In addition, as we are offering a degree programme, this will enable the institution to pursue research in related fields (Kyvik, \& Skodvin, 2003). However, the biggest challenge for this scenario is whether UoTs will have enough resources to offer both qualifications and pursue research in the related fields.

\section{Conclusion}

Apart from the two scenarios sketched above, the in principle question remains unanswered. Should UoTs offer only degrees and discontinue diplomas? The answer to this question in embedded in the response to the challenge of how the $\mathrm{HE}$ system will provide for a cohort of school leavers who do not qualify for degree qualifications. Clearly, diploma qualifications have a role to play. It would be unethical for UoTs to propose that programmes that historically empower the poor and disadvantaged sector of the society are closed down. On the other hand, is it ethical to train a workforce for 
the world of work that will be disempowered because of an inadequate qualification? The answer probably lies in diplomas that are designed to be used as a pathway that would assist in addressing equity and redress into higher education. In other words, a diploma that provides access into higher education degree qualification while at the same time dealing with education and training needs at regional and local levels (Shay, 2011; Young 2009; Gamble, 2006).

In addition, this article also explored the question that if the preference of industry is implemented, would there be enough practically skilled employees within industry? The answer is clearly no.

\section{References}

Ashworth, P.D., Gerrish, K., Hargreaves, J. \& McManus, M. (1999). 'Levels' of attainment in nursing practice: reality or illusion? Journal of Advances Nursing, 30 (1), 159-168.

Australian Qualifications Framework Council. (2013). Australian Qualifications Framework. Second Edition. January 2012. ISBN: 978-0-98705622-1. Retrieved July 29, 2013 from www.aqf.edu.au.

Beddie, F. (2010). The place of VET in the tertiary sector. A conference paper delivered as a keynote address on 24 May 2010 at VISTA Annual Conference: VET - The Invisible Sector. The National Centre for Vocational Education Research.

Edwards, R., \& Miller, K. (2008). Academic drift in vocational qualifications? Explorations through the lens of literacy. Journal of Vocational Education \& Training. 60 (2), 123-131.

Gamble, J. (2006). Theory and practice in the vocational curriculum. In Young, M., and Gamble, J., (Eds.). (2006). Knowledge, curriculum and qualifications for South African Further Education. Compiled by the Education, Science and Skills Development Research Programme of the Human Sciences Research Council. HSRC Press. Retrieved June 24, 2013 from http://www.hsrcpress.ac.za

Jinabhai, D.C. (2003). On the proposed new funding framework- a trajectory for growth or negative entropy for research at technikons. South African Journal for Higher Education. 17 (1), 55-60.

Kell, C. (2006). An analysis of entry level postgraduate students' readiness for student centred masters level learning. Learning in Health and Social Care. 5 (3), 133-141.

Kloppenborg, P. (2010). Higher education in TAFE: A new 'mixed sector' Library paradigm. Australian Academic and Research Libraries. 4 (3), 192-206.

Kyvik, S. \& Skodvin, O. (2003). Research in the non-university education sector- tensions and dilemmas. Higher Education. (45), $203-222$.

Lepori, B. (2008). Research in non-university higher education institutions. The case of the Swiss University of Applied Sciences. Higher Education. 56, 45-58.

Muller, J. (2013). Lecture presented to the Cape Higher Education Consortium Seminar 'Reviewing revising and developing the curriculum'. Cape Peninsula University of Technology, Bellville Campus, 27 February 2013.

Muller, J. (2009). Forms of knowledge and curriculum coherence. Journal of Education and Work. 22 (3), 205-226.

Önkal, D., Sayım, K.Z., \& Gönül. M.S. (2013). Scenarios as channels of forecast advice. Technological Forecasting \& Social Change. 80, $772-$ 788.

Pratt, J. (1997). The Polytechnic Experiment 1965 - 1997. Buckingham: The Society for Research into Higher Education and Open University Press.

Republic of South Africa. (2013). The Higher Education Qualification sub-Framework: As revised January 2013. Government Gazette No. 36003 of 14 December 2012 in terms of the National Act, 2008 (Act No 67 of 2006 and as contemplate in the Higher Education Act, 1997 (Act No. 101 of 1997).

Republic of South Africa (1997). White Paper 3: A programme for higher education transformation. Ministry of Education and Training. Government printers.

Sá, C.M., \& Litwin, J., (2011). University-industry research collaboration in Canada: the role of federal policy instruments. Science and Public Policy. 38 (6), 425-435

Shay, S., \& Steyn, D. (2013). Enabling Knowledge progression in vocational curricula: Design, as a case study. In Maton, K., Hood, S., \& Shay, S. (Eds.) (2013). Knowledge building: Educational Studies in Legitimation Code Theory. London. Routledge. [In press].

Shay, S. (2012). Educational development as a field: are we there yet? Higher Education and Research \& Development. 31(3), 311-323.

Shay, S., Oosthuizen M, Paxton, P. \& van de Merwe, R. (2011). Towards a principled basis for curriculum differentiation: Lessons from a comprehensive university. In Blitzer, E., \& Both, M. (Eds.). (2011). Curriculum inquiry in a South African higher education. 101 - 120. Stellenbosch: Sun Media Retrieved August, 062013 from http://www.academia.edu/1432834/Towards_a_ principled_ basis_for_curriculum_differentiation_Lessons_from_a_comprehensive_university.

Snoek, M. (2003). The use and methodology of scenario mäking. European Journal of Teacher Education. 26 (1), 9-19.

Statistics South Africa. (2012). Census 2011. Statistical Release (Revised) P0301.14. Statistics South Africa. Pretoria.

Warring, S. (2011). An analysis of learning levels within and between a degree and a diploma: New Zealand Case Study. Quality Assurance in Education. 19 (4), 441- 450.

Winberg, C. (2012). Diplomas and degrees in professionally-oriented higher education. Unpublished position paper prepared for CPUT Senate Academic Planning Committee.

Wright, G., Cairns, G., \& Bradfield, R. (2013). Scenario methodology: New developments in theory and practice Introduction to the Special Issue Technological. Forecasting \& Social Change. 80, 561-565.

Young, I. (2009). Building better pathways to higher education. Retrieved June 20, 2013 from http://www.swinburne.edu.au/corporate/ marketing/medicentre/core/content/pathways.pdf .

Young, P. (1975). Alternatives in Education - A liberal policy for Australian tertiary education. Retrieved June 21, 2013 from: http://www.eric.ed.gov/PDFS/EJ124509. 